\title{
Defective jejunal brush border membrane sodium/ proton exchange in association with lethal familial protracted diarrhoea
}

\author{
K M Keller, S Wirth, W Baumann, D Sule, I W Booth
}

\begin{abstract}
The spectrum of clinical disease associated with specific defects in jejunal brush border membrane sodium/proton exchange is poorly defined and only two patients have been described so far. Jejunal brush border membrane transport studies were performed in a boy who presented with lethal familial protracted diarrhoea in the first few days of life. Using jejunal brush border membrane vesicles prepared from conventional jejunal biopsy specimens, initial sodium uptake under $\mathrm{H}^{+}$gradient conditions was found to be only $6 \%$ of the mean control value. In contrast, sodium stimulated glucose uptake was normal. Our data confirm the importance of a congenital defect in this exchanger as a cause of severe sodium-losing diarrhoea and extend the spectrum of disorders characterised by a specific defect in brush border membrane $\mathrm{Na}^{+} / \mathrm{H}^{+}$exchange to include some forms of lethal familial protracted diarrhoea.
\end{abstract}

A wide variety of disorders is responsible for severe protracted diarrhoea in infancy. ${ }^{1}$ Investigations in familial protracted diarrhoea, however, usually fail to detect a clearly defined pathophysiological cause, ${ }^{2}$ although some cases may be associated with microvillus atrophy. ${ }^{34}$ Congenital brush border membrane defects are now established for sodium dependent glucose transport (glucose-galactose malabsorption) $)^{5}$ and for the $\mathrm{Cl} / \mathrm{HCO}_{3}^{-}$exchanger (congenital chloridorrhoea). ${ }^{6-9}$ Recently, a defect in brush border membrane sodium/proton exchange was also described $^{10}$ and a second patient with this disorder has been reported." We present a further child with a specific defect in this exchanger, who presented with lethal sodium-losing familial protracted diarrhoea in the first few days of life.

K M Keller
S Wirth

W Baumann

Institute of Child Health, University of Birmingham D Sule I W Booth

Correspondence to: Dr I W Booth, University of Birmingham, Nuffield Building, Institute of Child Health, Francis Road Birmingham B16 8ET.

Accepted for publication 1 December 1989

\section{Case report}

The patient, a boy, was born after a normal pregnancy and weighed $2900 \mathrm{~g}$. There was no history of hydramnios and the parents were unrelated. Two previous siblings, both girls, had died of severe protracted diarrhoea at 2 and 11 months of age; both had had very high stool sodium concentrations $(>80 \mathrm{mmol} / \mathrm{l})$.

The patient passed normal meconium within
24 hours, but watery stools began on the third day of life. He was formula fed and admitted to hospital on the sixth day of life with profuse watery diarrhoea, profound dehydration, and a severe metabolic acidosis ( $\mathrm{pH}: 7 \cdot 02$; base excess: $-27 \mathrm{mmol} / \mathrm{l}$ ). Parenteral nutrition was started but profuse diarrhoea persisted. At the age of 3 weeks he developed severe necrotising enterocolitis and required an ileostomy. A high output secretory diarrhoea $(60-90 \mathrm{ml} / \mathrm{kg} /$ day $)$ persisted, despite receiving nil by mouth (ileostomy fluid (mmol/l): $\mathrm{Na} \mathrm{128,} \mathrm{K} \mathrm{10}, \mathrm{Cl} \mathrm{96)}$ and subsequent reanastomosis (stools (mmol/l): $\mathrm{Na} 90, \mathrm{~K} 38$, $\mathrm{Cl}$ 72). His parenteral sodium requirement was high (6-10 mmol/kg/day) and remained so after reanastomosis. A persistent metabolic acidosis was present (base excess: -6 to $-20 \mathrm{mmol} / \mathrm{l}$ ), but there was no evidence of a renal tubular defect. Plasma aldosterone concentrations were raised, probably secondary to persisting marginal sodium depletion.

Extensive investigation of gastrointestinal function failed to show the cause of the diarrhoea. Tests of immune function (circulating immunoglobulins, E rosette formation, mitogen stimulation of lymphocyte, chemiluminescence and autoantibodies (including antienterocyte antibody), and gastrointestinal peptides (vasoactive intestinal peptide, pancreatic polypeptide, and gastrin) were all normal. Radiological findings in the gastrointestinal tract were unremarkable, and jejunal and ileal biopsy specimens showed mild partial villous atrophy but looked normal on electron microscopy. Mucosal disaccharidase activities were somewhat reduced (IU/g protein: lactase 14.9 (reference mean (SD) 65 (45)); sucrase $15 \cdot 1$ (reference mean (SD) 75 (50)) probably as a result of prolonged parenteral nutrition. Enzyme histochemistry of colonic biopsy specimens showed normal nerve fibres.

Brush border membrane vesicles prepared from a jejunal biopsy specimen performed when the boy was 4 months old showed a gross defect in sodium/proton exchange, but normal sodiumstimulated D glucose transport.

The boy was maintained on home parenteral nutrition because of intolerance of all enteral feeds other than small amounts of $10 \%$ glucose or Ringer's solution. He grew along the 3rd centiles for height and weight, but developed increasing cholestasis and died of severe intercurrent infection at 18 months. 
Jejunal brush border membrane vesicle studies

CONTROL SUBJECTS

Histologically normal jejunal biopsy specimens were obtained from two sources:

(a) Partial thickness specimens (epithelium plus submucosa), weighing $20-50 \mathrm{mg}$, were obtained per orally from five patients (aged 1 to 6 years) being investigated for gastrointestinal symptoms, but subsequently shown to have no organic disease.

(b) Full thickness specimens weighing 90$150 \mathrm{mg}$, were obtained surgically from 10 patients (aged 2 to 7 months), undergoing a portoenterostomy procedure for extrahepatic biliary atresia.

The specimens were rinsed rapidly in $0 \cdot 15 \mathrm{M}$ $\mathrm{NaCl}$ solution and stored in air tight containers at $-70^{\circ} \mathrm{C}$. There were no differences in the transport characteristics of vesicles prepared from the two sources.

All studies were carried out with the approval of the local research ethical committee and the written informed consent of the patient's parents.

\section{Methods}

\section{ISOLATION OF VESICLES}

Vesicles were prepared from biopsy specimens using a previously described technique. ${ }^{510}$ In the case of peroral jejunal biopsy specimens, 20-50 $\mathrm{mg}$ frozen mucosa were thawed in $200 \mu \mathrm{l}$ mannitol buffer containing (in $\mathrm{mmol} / \mathrm{l}$ ): mannitol 300; ethylene glycol tetra-acetic acid 5, Tris $/ \mathrm{HCl} 12, \mathrm{pH} 7 \cdot 1$. The buffer plus mucosa was diluted sixfold by volume with ice cold deionised water and homogenised for one minute (Sorvall Mini-Omnimixer, speed 5).

When using full thickness jejunal specimens taken at operation, $100-150 \mathrm{mg}$ gut were thawed in $200 \mathrm{ul}$ mannitol buffer, diluted sixfold with ice cold, deionised water, and vibrated for two minutes (Vibro Mischer El, Chemap AG). After removal of any intestinal muscle with forceps, the material was homogenised as above.

Magnesium chloride was added to the homogenate to a final concentration of $10 \mathrm{mmol} / \mathrm{l}$, and after standing on ice for $\mathbf{4 0}$ minutes, the specimen was centrifuged for 15 minutes at $3000 \mathrm{~g}$ at $4^{\circ} \mathrm{C}$. The supernatant $(\mathrm{I})$ was removed and stored on ice.

The pellet was resuspended in $1 \mathrm{ml}$ buffer containing (in $\mathrm{mmol} / \mathrm{l}$ ): mannitol 60 , ethylene glycol tetra-acetic acid 1, Tris/HCl 2.4, $\mathrm{pH} 7 \cdot 1$ and homogenised with a glass Teflon tissue homogeniser. After addition of $\mathrm{MgCl}_{2}$ (10 $\mathrm{mmol} / \mathrm{l}$ ) and standing on ice for 15 minutes, the homogenate was centrifuged for 15 minutes at $3000 \mathrm{~g}$ at $4^{\circ} \mathrm{C}$.

The supernatant (II) was added to supernatant I and the combined supernatants were centrifuged for 30 minutes at $27000 \mathrm{~g}$ at $4^{\circ} \mathrm{C}$. The resulting pellet was resuspended in a small volume of membrane buffer (about $125 \mu \mathrm{l}$ ) by means of a syringe and $25 \mathrm{G}$ needle.

The membrane suspension was equilibrated at room temperature and $4^{\circ} \mathrm{C}$ for 30 minutes each, before transport studies.
ENZYME ASSAYS AND PROTEIN DETERMINATIONS

Two microvillus marker enzymes were used to assess brush border membrane purification. Alkaline phosphatase (EC 3.1.3.1) activity was measured using a fluorimetric procedure ${ }^{12}$ with $0.1 \mathrm{~mm}$ methyl umbelliferyl dihydrogen phosphate as substrate in borate buffer, $\mathrm{pH} 8.8$, containing $5 \mathrm{mmol} / \mathrm{l} \mathrm{MgCl}_{2}$ and $0.1 \%$ Triton $\mathrm{X}-100$; sucrase (EC 3.2.1.48) activity was determined fluorimetrically, ${ }^{13}$ using $0.028 \mathrm{M}$ sucrose as substrate. The glucose product was measured by glucose oxidase-peroxidase with homovanillic acid as fluorogen.

Protein measurements were made with the Coomassie blue dye binding method, ${ }^{14}$ using the Bio-Rad protein assay kit.

Both brush border marker enzymes were measured in whole tissue homogenates and in the final vesicle preparations. Specific enzyme activities were enhanced 15 to 20 -fold in the vesicle preparations.

\section{TRANSPORT STUDIES}

As a method control for confirming the integrity of brush border membrane vesicles, intact sodium stimulated D glucose uptake was confirmed in a fraction of each vesicle preparation. This requires showing that an inwardly directed sodium gradient ( $\mathrm{Na}$ out $>\mathrm{Na}$ in) enhances glucose uptake, when compared with uptake without such a gradient $(\mathrm{Na}$ in $=\mathrm{Na}$ out $)$. Brush border membrane vesicles were therefore preloaded with one of two buffers, containing either (in $\mathrm{mmol} / \mathrm{l}$ ): mannitol 300 and Hepes-Tris 50 (pH 7.4); or mannitol 100, Hepes-Tris $50(\mathrm{pH}$ $7 \cdot 4$ ), and $\mathrm{NaCl} 100$, and incubated in a medium containing (mmol/l): mannitol 100, Hepes-Tris $50(\mathrm{pH} 7 \cdot 4), \mathrm{NaCl} 100$, and $\mathrm{D}$ glucose $0 \cdot 1\left(+{ }^{3} \mathrm{H}\right.$ $\mathrm{D}$ glucose tracer).

To show the presence or absence of sodium/ proton exchange requires proof that an outwardly directed proton gradient $(\mathrm{pH}$ in $<\mathrm{pH}$ out) enhances sodium uptake, when compared with uptake without such a gradient $(\mathrm{pH}$ in $=\mathrm{pH}$ out $)$. Vesicles were therefore preloaded with a buffer containing (in mmol/l): mannitol $300,2(\mathrm{~N}$ morpholino)-ethane sulphonic acid (MES) Tris (pH 6.0) $50, \mathrm{~K}^{+}$gluconate $20,0 \cdot 1 \mathrm{mg} / \mathrm{ml}$ valinomycin, and incubated in a medium containing (in mmol/l): mannitol $300, \mathrm{NaCl} 0 \cdot 1\left(+{ }^{22} \mathrm{Na}\right.$ tracer), $\mathrm{K}^{+}$gluconate 20 , and either Hepes-Tris $50(\mathrm{pH} \mathrm{7 \cdot 4)}$ or MES-Tris 50 (pH 6.0).

The uptake of ${ }^{22} \mathrm{Na}$ or ${ }^{3} \mathrm{H} \mathrm{D}$ glucose (Amersham International) by brush border membrane vesicles after 15 seconds and 90 minutes (glucose) or 15 seconds and 120 minutes (sodium) incubation, was measured using a rapid filtration technique, ${ }^{15}$ with $74 \mathrm{kBq}{ }^{22} \mathrm{Na}$ or $185 \mathrm{kBq}{ }^{3} \mathrm{H} \mathrm{D}$ glucose per time point.

\section{Results}

In brush border membrane vesicles from controls and the patient, an inwardly directed sodium gradient resulted in appreciable enhancement of $D$ glucose uptake at 15 seconds; such that there was no significant difference in sodium stimulated D glucose uptake between controls and the patient (Figure). 
$D$ glucose and $\mathrm{Na}^{+}$uptake in brush border membrane vesicles from controls and in a patient with defective $\mathrm{Na}^{+}$I $\mathrm{H}^{+}$exchange.

(a) D glucose uptakes in the presence and absence of an inwardly directed $\mathrm{Na}^{+}$ gradient. (b) $\mathrm{Na}^{+}$uptakes in the presence $(+)$ and absence (-) of an outwardly directed $\mathrm{H}^{+}$gradient. The incubation media and membrane buffers used are given in the text. The control values are shown as means (SEM).

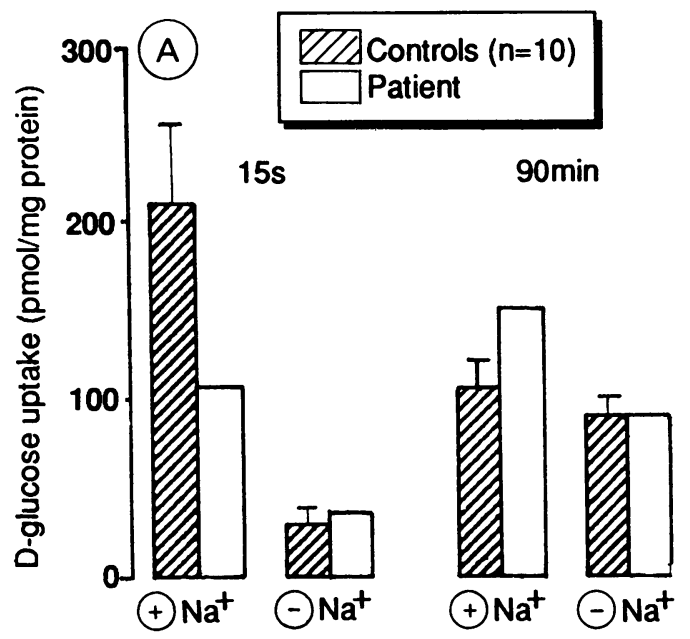

In contrast, brush border membrane vesicles from the patient showed no 15 seconds enhancement of sodium uptake under conditions of an outwardly directed proton gradient, when compared with no gradient; a sevenfold enhancement was seen in controls. As a result, 15 seconds sodium uptake under proton-gradient conditions was only $9 \mathrm{pmol}$ sodium $/ \mathrm{mg}$ protein in brush border membrane vesicles from the patient, compared with a mean (SD) uptake in controls of $150(48) \mathrm{pmol}$ sodium/mg protein.

Equilibrium values at 90 minutes (glucose) and 120 minutes (sodium) were not significantly different.

\section{Discussion}

The spectrum of clinical disease associated with the recently described specific defect in jejunal brush border membrane sodium/proton exchange is poorly defined. ${ }^{10} 1$ The clinical presentation and course of the two children published so far resembled congenital chloridorrhoea, ${ }^{9}$ with a secretory diarrhoea beginning in utero with hydramnios, and a favourable prognosis. Both children grew and developed normally on appropriate electrolyte supplements.

Our patient had an equally severe and specific defect in jejunal brush border membrane sodium/proton exchange in vitro - again in association with intractable sodium-losing diarrhoea and a metabolic acidosis. A number of important clinical differences, however, were present. There was no evidence of true congenital diarrhoea, in that a history of hydramnios was absent, and the fatal outcome, strong family history, and prolonged dependence upon parenteral nutrition all suggest a different disease.

It is not clear to what extent the development of severe necrotising enterocolitis at 3 weeks of age may have enhanced any postnatal differences between our patient and those previously

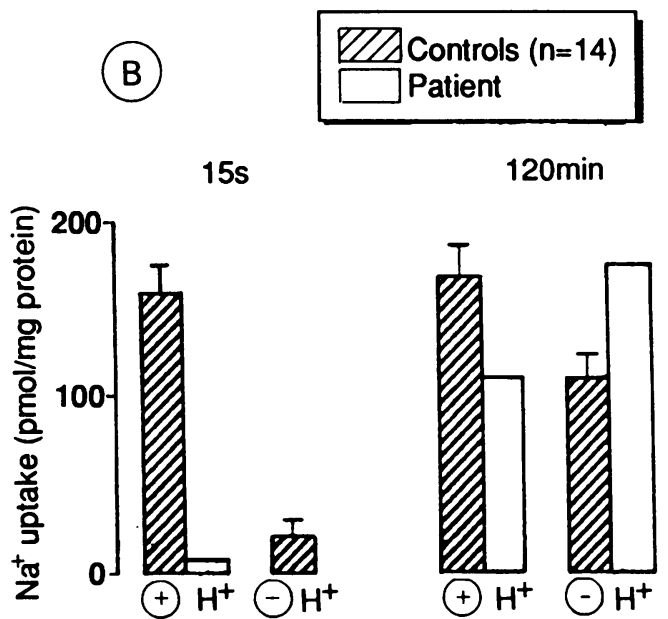

reported with a similar defect. The presence of normal D glucose transport in our patient's brush border membrane vesicles does make it clear, however, that the observed changes in sodium transport did not result from unresolved non-specific mucosal damage after necrotising enterocolitis.

Our observations therefore confirm the importance of defective jejunal sodium/proton exchange as a cause of severe sodium-losing diarrhoea and extend the limited range of brush border membrane defects known to occur in association with lethal familial protracted diarrhoea.

1 Branski D. Specific etiologies of chronic diarrhea in infancy. In: Lebenthal E, ed. Chronic diarrhea in children. New York: In: Lebenthal E, ed: Chrons.

2 Candy DCA, Larcher V, Cameron DJS, et al. Lethal familial protracted diarrhoea. Arch Dis Child 1981; 56: 15-23.

3 Davidson GP, Cutz E, Hamilton JR, Gall DG. Familial enteropathy: a syndrome of protracted diarrhoea from birth, failure to thrive and hypoplastic villus atrophy. Gastroenterology 1978; 75: 783-90.

4 Cutz E, Rhoads JM, Drumm B, Sherman PM, Durioe PR, Forstner GG. Microvillus inclusion disease: an inherited defect of brush border assembly and differentiation. $N E n g$ f Med 1989; 320: 646-51.

5 Booth IW, Patel PB, Sule D, Brown GA, Buick R, Beyreiss K. Glucose-galactose malabsorption: demonstration of specific jejunal brush border membrane defect. Gut 1988; 29 : $1661-5$.

6 Turnberg LA. Abnormalities in intestinal electrolyte transport in congenital chloridorrhoea. Gut 1971; 12: 544-51.

7 Bieberdorf PA, Gorden P, Fordtran JS. Pathogenesis of congenital alkalosis with diarrhoea. Implications for the physiology of normal ileal electrolyte absorption and secretion. 7 Clin Invest 1972; 51: 1958-68.

8 Holmberg C, Perheentupa J, Launiala K. Colonic electrolyte transport in health and in congenital chloride diarrhoea. f Clin Invest 1975; 56: 302-10.

9 Holmberg C, Perheentupa J, Launiala K, Hallman N Congenital chloride diarrhoea - clinical analysis of 21 Finnish patients. Arch Dis Child 1977; 52: 255-67.

10 Booth IW, Stange G, Murer H, Fenton TR, Milla PJ. Defective jejunal brush-border $\mathrm{Na}^{\prime} / \mathrm{H}^{\prime}$ exchange: a cause of congenital secretory diarrhoea. Lancet 1985; i: 1066-9.

11 Holmberg C, Perheentupa J. Congenital $\mathrm{Na}$ diarrhoea: a new type of secretory diarrhoea. $\mathcal{F}$ Pediatr 1985; 106: 56-61.

12 Peters TJ, Muller M, De Duve C. Lysosomes of the arterial wall. I. Isolation and subcellular fractionation of cells from normal rabbit aorta. F Exp Med 1972; 136: 1117-39.

13 Peters TJ, Batt RM, Heath JR, Tilleray J. The microassay of intestinal disaccharidases. Biochem Med 1976; 15: 145-8.

14 Bradford MM. A rapid and sensitive method for the quantitation of microgram quantities of protein utilising the principle of protein-dye binding. Anal Chem 1976; 72:248 54. 